\title{
A Convenient and Efficient Method for Demethylation of Aryl Methyl Ethers with Magnesium Iodide in Ionic Liquid
}

\author{
Kwan Soo Lee ${ }^{\dagger}$ and Kee D. Kim* \\ Department of Fine Chemical and Advanced Materials, Sangji University, Wonju 220-702, Korea \\ ${ }^{*}$ E-mail: kdkim@sangji.ac.kr \\ ${ }^{\dagger}$ Department of Chemistry, KAIST, Daejeon 305-701, Korea \\ Received August 25, 2010, Accepted September 29, 2010
}

Key Words: Demethylation, Ionic liquid, Magnesium, Phenols

Demethylation of aryl methyl ethers to the corresponding phenols are very important reactions in organic synthesis. ${ }^{1,2} \mathrm{~A}$ number of methods have been reported for the cleavage of highly stable aryl methyl ethers utilizing strong acids or bases such as aluminum chloride, ${ }^{3}$ boron tribromide, ${ }^{4}$ cerium chloride, ${ }^{5}$ alkaline thiolate, ${ }^{6}$ methyl magnesium iodide, ${ }^{7}$ and L-Selectride. ${ }^{8}$ However, all of these methods invariably suffered from one or more drawbacks such as harsh reaction conditions, long reaction times, difficulty of manipulation, use of exotic reagents, and low reaction yields. Furthermore, in the most of known methods for demethylation of aryl methyl ethers, use of large excess amounts of demethylating agents have been generally required. Thus, it is highly desirable to develop an improved convenient and efficient procedure for demethylation reactions of aryl methyl ethers.

Magnesium iodide etherate, $\mathrm{MgI}_{2}(\mathrm{OEt})_{2}$, freshly prepared in situ by treatment of magnesium solid with iodine in dry ethyl ether solution, has been utilized for the deprotection of aryl methyl ethers. ${ }^{9-11}$ However, this method is ineffective for the deprotection of simple aryl methyl ethers and only applicable to the cleavage of activated phenolic $O$-methyl group present ortho to the carbonyl group. Moreover, $\mathrm{MgI}_{2}(\mathrm{OEt})_{2}$ promoted demethylation reactions of 2-methoxy benzaldehyde derivatives have been always conducted in toxic organic solvents such as benzene, THF, and ethyl ether.

During the course of our search for the safe and practical reagent systems, we observed that readily available and non-toxic

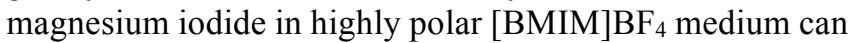
efficiently promoted the demethylation reactions of aryl methyl ethers. To the best of our knowledge, reports with combination of magnesium iodide and ionic liquid for the demethylation of aryl methyl ethers have not appeared so far.

Herein, we wish to report a new efficient method for the demethylation of aryl methyl ethers utilizing combination of readily available and stable magnesium iodide with environmentally friendly ionic liquid under mild reaction conditions. Treatment of aryl methyl ethers with magnesium iodide (1.5 equiv.) in 1-butyl-3-methylimidazolium tetrafluoroborate, [BMIM] $\mathrm{BF}_{4}$, ionic liquid at $50{ }^{\circ} \mathrm{C}$ for $4-7 \mathrm{~h}$ afforded demethylated

$$
\mathrm{ArOCH}_{3} \underset{[\mathrm{BMIM}] \mathrm{BF}_{4}}{\mathrm{Mgl}} \mathrm{ArOH}
$$

phenolic products in high yield. Change of ionic liquid medium

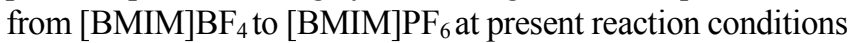
produced much lower yields of desired demethylated products. In all of the cases examined, the demethylation reactions proceeded smoothly for removal of methyl group on the various aryl methyl ethers as shown in the Table 1 . The generality of present method are exemplified in the successful demethylation reactions of substrates containing various sensitive functional groups including $\mathrm{CHO}, \mathrm{COCH}_{3}$, and $\mathrm{COOCH}_{3}$. It is also note-

Table 1. Demethylation of aryl methyl ethers with $\mathrm{MgI}_{2}$ in ionic liquid

28


worthy that present method proved to be very effective for the demethylation of unactivated aryl methyl ethers which is hard to expect to in the other reported methods utilizing $\mathrm{MgI}_{2}(\mathrm{OEt})_{2}$. The high reactivity of magnesium iodide at present reaction conditions could possibly be explained by the enhancement of nucleophilicity of idodide as a result of increased charge separation in the transition state under [BMIM] $\mathrm{BF}_{4}$. This result is analogous to the observations reported in halide induced nucleophilic substitution reactions in ionic liquid..$^{12,13}$

In conclusion, we have developed a new and efficient method for the demethylation of various types of aryl methyl ethers using readily available, stable, and easily handled magnesium iodide in [BMIM]BF 4 ionic liquid. Owing to its simplicity and mild reaction conditions the protocol reported herein may serve as a useful alternative to the existing methods for the deprotection of aryl methyl ethers to the corresponding phenolic derivatives.

\section{Experimental Section}

All solvents and reagents were of reagent grade. Merck precoated silica gel plates with fluorescent indicator $\left(60 \mathrm{~F}_{254}\right)$ were used for analytical thin layer chromatography. Flash column chromatography was performed using Merck silica gel 60 (230 400 mesh ASTM). ${ }^{1} \mathrm{H}$ NMR spectra were recorded on a Varian Gemini 2000 (300 MHz) spectrometer in $\mathrm{CDCl}_{3}$.

A general synthetic procedure for demethylation of aryl methyl ethers is as follows.

To a solution of aryl methyl ether $(1.0 \mathrm{mmol})$ in $[\mathrm{bmim}] \mathrm{BF}_{4}$ $(2 \mathrm{~mL})$ was added magnesium iodide $(0.42 \mathrm{~g}, 1.5 \mathrm{mmol})$. The reaction mixture was stirred at $50{ }^{\circ} \mathrm{C}$ for $4-7 \mathrm{~h}$. After addition of $5 \%$ aqueous sodium thiosulfate $(10 \mathrm{~mL})$, the product was extracted with ether $(2 \times 10 \mathrm{~mL})$, washed with brine $(5 \mathrm{~mL})$, and dried over $\mathrm{MgSO}_{4}$. The solvent was removed in vacuo and the crude mixture was purified by silica gel chromatography using ethyl ether:hexane (1:3) as eluent to give the desired phenolic product.

Acknowledgments. This research was supported by Sangji University Research Fund, 2010.

\section{References}

1. Wuts, P. G. M.; Green, T. W. Greens's Protective Groups in Organic Synthesis, 4th ed.; John Wiley \& Sons: New Jersey, 2007; p 370 and references therein.

2. Maercker, A. Angew. Chem. Int. Ed. Engl. 1987, 26, 972.

3. Parker, K. A.; Petraitis, J. J. Tetrahedron Lett. 1981, 22, 397.

4. Miller, J. M.; So, K. H.; Clark, J. H. Can. J. Chem. 1979, 57, 1887.

5. Yadav, J. S.; Reddy, B. V. S.; Madan, C.; Hashim, S. R. Chem. Lett. 2000, 29, 738.

6. Dodge, J. A.; Stocksdale, M. G.; Fahey, K. J.; Jones, C. D. J. Org. Chem. 1995, 60, 739.

7. Mechoulam, R.; Gaoni, Y. A. J. Am. Chem. Soc. 1965, 87, 3273.

8. Majetich, G.; Zhang, Y.; Wheless, K. Tetrahedron Lett.1994, 35 , 8727.

9. Yamaguchi, S.; Sugiura, K.; Fukuoka, R.; Okazaki, K.; Takeuchi, M.; Kawase, Y. Bull. Chem. Soc. Jpn. 1984, 57, 3607.

10. Yamaguchi, S.; Nedachi, M.; Yokoyama, H.; Hirai, Y. Tetrahedron Lett. 1999, 40, 7363.

11. Snyder, S. A.; Tang, Z.-Y.; Gupta, R. J. Am. Chem. Soc. 2009, 131, 5744.

12. Lourenço, N. M. T.; Afonso, C. A. M. Tetrahedron 2003, 59, 789.

13. Judeh, Z. M. A.; Shen, H.-Y.; Chi, B. C.; Feng, L.-C.; Selvasothi, S. Tetrahedron Lett. 2002, 43, 9381.

14. Boovanahalli, S. K.; Kim, D. W.; Chi, D. Y. J. Org. Chem. 2004, 69,3340 . 